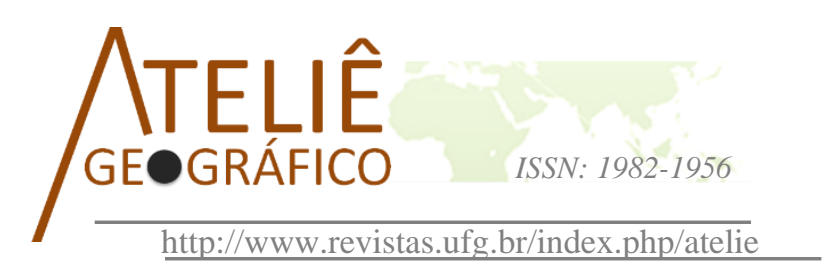

\title{
Análise da disposição de resíduos sólidos urbanos em Minas Gerais e em cidades médias do Grupo Bambuí
}

\author{
Analysis of the disposal of solid urban waste in Minas \\ Gerais and in medium-sized cities of the Bambui Group
}

Análisis de la disposición de residuos sólidos urbanos en

Minas Gerais y en ciudades medianas del Grupo Bambuí

Isabela Dalle Varela

Centro Universitário Newton Paiva e Faculdade de Direito Promove. Academia da Polícia Militar de Minas Gerais

dallevarela@gmail.com

Luiz Eduardo Panisset Travassos

Pontifícia Universidade Católica de Minas Gerais (PUC Minas)

luizepanisset@gmail.com

\begin{abstract}
Resumo
Minas Gerais possui aproximadamente $580.000 \mathrm{~km}^{2}$ e cerca de $29.000 \mathrm{~km}^{2}$ são desenvolvidos em carbonatos. Com 853 municípios, uma grave questão é a disposição final de resíduos sólidos urbanos (RSU), particularmente em cidades médias. Desde 2000, instrumentos legais foram publicados para disciplinar a disposição de RSU, embora a realidade esteja longe de ser ideal. Assim, a pesquisa analisou a disposição de RSU em Minas Gerais, de 2008 a 2015, especificamente nas cidades médias desenvolvidas sobre os carbonatos do Grupo Bambuí. Estabeleceu-se a relação entre o direito fundamental à saúde e a necessidade de se proteger o carste e seus aquíferos para manutenção da qualidade ambiental. Dos 167 municípios desenvolvidos sobre o carste, 34 possuem cidades médias. Os resultados demonstram que o direito à saúde e ao saneamento podem ser comprometidos devido à falta de estudos sobre a importância do carste na manutenção da qualidade ambiental e sobre como as cidades médias devem se desenvolver quando sobre esse frágil geossistema.

Palavras-Chave: Direito à saúde, Cidades Médias, Carste, Minas Gerais.
\end{abstract}

\begin{abstract}
Minas Gerais has approximately $580,000 \mathrm{~km}^{2}$, and about $29,000 \mathrm{~km}^{2}$ developed in carbonate rocks. With 853 municipalities and environmental problems, a severe issue is the disposal of solid urban waste, particularly in medium-sized cities. Since 2000, legal instruments have been published to discipline the subject, although the reality is far from ideal. Therefore, the researchers analyzed the disposition of urban waste in
\end{abstract}


Minas Gerais, from 2008 to 2015, specifically in the medium-sized cities developed on the Bambuí Group. A relationship is established between the fundamental right to health and the need to protect karst and its aquifers to maintain environmental quality. Of the 167 municipalities developed on covered or exhumed karst, 34 have mediumsized cities. Preliminary results demonstrate that the right to health and sanitation may be compromised due to the lack of studies on the importance of karst in maintaining environmental quality and how medium-sized cities should develop when it comes to this fragile geosystem.

Keywords: Environment, Karst, Minas Gerais, Mid-sized Cities, Right to Health.

\begin{abstract}
Resumen
Minas Gerais tiene aproximadamente $580.000 \mathrm{~km}^{2}$ y $29.000 \mathrm{~km}^{2}$ desarrollados en rocas carbonatadas. Con 853 municipios y problemas ambientales, un problema grave es la disposición final de residuos sólidos urbanos, particularmente en ciudades de tamaño medio. Desde 2000, se han publicado instrumentos legales para disciplinar la disposición de residuos urbanos, pero la realidad no sea ideale. Por tanto, la investigación analiza la disposición de residuos urbanos en Minas Gerais, de 2008 a 2015, específicamente en las ciudades medias desarrolladas sobre los carbonatos del Grupo Bambuí. Se establece una relación entre el derecho fundamental a la salud y la necesidad de proteger el karst y sus acuíferos para mantener la calidad ambiental en estas regiones. De los 167 municipios que se desarrollaron sobre el carso, 34 teníen ciudades de tamaño medio. Los resultados preliminares mostraron que la salud y el saneamiento podrían verse comprometidos debido a la carencia de estudios sobre la importancia del carso en el mantenimiento de la calidad ambiental y cómo desarrollar estas ciudades medianas cuando se trata de este frágil geosistema.
\end{abstract}

Palabras clave: Derecho a la salud, Ciudades medianas, Carso, Minas Gerais.

\title{
Introdução
}

O acelerado processo de industrialização brasileira, iniciado a partir dos anos 70, intensificou a produção de resíduos domésticos e industriais. Com o aumento da população, muitos setores industriais passaram a direcionar seus esforços para a busca de alternativas aos resíduos, especialmente com a intenção de diminuir o envio desses para aterros ou locais inapropriados para disposição. Quando não tratados adequadamente os resíduos sólidos urbanos (RSU) e, principalmente, os industriais, possuem elementos químicos tóxicos, que se tornam perigosos passivos ambientais e atingem tanto o meio ambiente, quanto a saúde pública (COSTA, 2009; CRUZ; HUPFFER; JAHNO, 2016).

De acordo com Souza et al. (2016), o gerenciamento adequado dos resíduos sólidos, especialmente os domiciliares, é considerado um dos maiores desafios da sociedade moderna, devido aos aspectos ambientais, sanitários, sociais e econômicos envolvidos. Ainda segundo esses autores, pensar na importância de um gerenciamento de resíduos sólidos é, entre outras coisas, pensar na qualidade de vida dos cidadãos.

A nova consciência ambiental, surgida no conjunto das transformações culturais que ocorreram nas décadas de 1960 e 1970, ganhou dimensão cada vez maior e fixou a proteção do meio ambiente como um dos princípios mais fundamentais da modernidade. Os RSU se tornaram um dos maiores desafios do século XXI, com reflexos que extrapolam a área ambiental em virtude do crescimento econômico e do contingente 
populacional dos centros urbanos, do acentuado consumo, da geração de resíduos em ritmos geométricos e do descarte inadequado dos materiais, provocando desperdício de matéria e energia (DONAIRE, 1994; COSTA, 2010; CRUZ; HUPFFER; JAHNO, 2016; SILVA et al., 2016).

A paisagem cárstica e as cavernas são fascinantes e ricas em recursos naturais. Em muitas cavernas, animais altamente especializados só existem nesses locais, oferecendo, conforme mencionado por Pipan e Culver (2013), nichos ecológicos únicos. Além disso, vestígios paleontológicos e arqueológicos são preservados nesses locais, como prova do seu uso ao longo da História. Sherwood e Simek (2001) afirmam que os muitos artefatos que documentam o desenvolvimento humano ao longo dos milênios são preservados no carste, atribuindo a essa paisagem, grande valor histórico e cultural

As várias formas de uso do carste e suas cavernas são a medida de sua importância. O termo "carste", utilizado para designar um tipo especial de relevo, tem origem em uma região europeia entre a Itália e a Eslovênia, o Carso e o Kras, abundantes em rochas carbonáticas. Assim, esse tipo de paisagem apresenta características morfológicas e hidrológicas específicas (e.g. dolinas, grandes planícies, cavernas e drenagem subterrânea etc.), cujo processo predominante é a dissolução, tanto na superfície quanto no subterrâneo. Mais de $20 \%$ da superfície terrestre é caracterizada por fenômenos cársticos externos ou internos. Por fim, os processos cársticos, juntamente com as passagens subterrâneas, formam um complexo sistema tridimensional de condutos capazes de armazenar e transmitir água (WHITE, 2002; FORD; WILLIAMS, 2007; GUTIERREZ et al., 2014; FORTI, 2015). De acordo com Barton e Northup (2007) e Forti (2015), além da variedade de fauna e flora que inclui espécies endêmicas no carste, as cavernas também são habitats para microrganismos únicos que auxiliam na sintetização de fármacos.

A Organização das Nações Unidas para a Educação, a Ciência e a Cultura (UNESCO) afirma que os aquíferos cársticos representam os mais significativos e seguros mananciais de água potável. Estima-se que cerca de $25 \%$ da população mundial seja abastecida por esse tipo de aquífero, com a possibilidade de aumento em razão da poluição crescente de aquíferos não-cársticos. Diversas cavernas estão abertas ao turismo pelo mundo por mais de 400 anos e quase todo país que possui carste possui pelo menos uma caverna aberta ao turismo. Estima-se que cerca de 250 milhões de pessoas visitam cavernas turísticas, movimentando o turismo local e regional, afetando direta ou indiretamente cerca de 100 milhões de pessoas que dependem das cavernas turísticas para sua sobrevivência. Esses números podem dobrar se levarmos em consideração o carste em si e os que são Unidades de Conservação (UC) ou Geoparques (FORD; WILLIAMS, 2007; AURELI, 2010; TRAVASSOS, 2010; CIGNA; FORTI, 2013; FORTI, 2015; TRAVASSOS, 2019).

O carste e as cavernas são ambientes extremamente frágeis que são direta e indiretamente afetados por impactos específicos, geralmente relacionados com suas peculiaridades geológicas, geomorfológicas, hidrológicas e ecológicas. A exploração minerária descontrolada pode prejudicar sistemas superficiais e subterrâneos, conforme 
destacam Parise e Pascali (2003). Mudanças no uso da terra também podem resultar em degradação do epicarste (WILLIAMS, 2008), que fornece funções vitais para os ecossistemas cársticos (PIPAN; CULVER, 2013). A conexão direta entre a superfície e os aquíferos abaixo dela faz com que as águas cársticas subterrâneas sejam extremamente vulneráveis à poluição, que pode ser rapidamente levada a sumidouros e nascentes (RAVBAR; GOLDSCHEIDER, 2009; FORTI, 2013), conforme resumido na Figura 1.

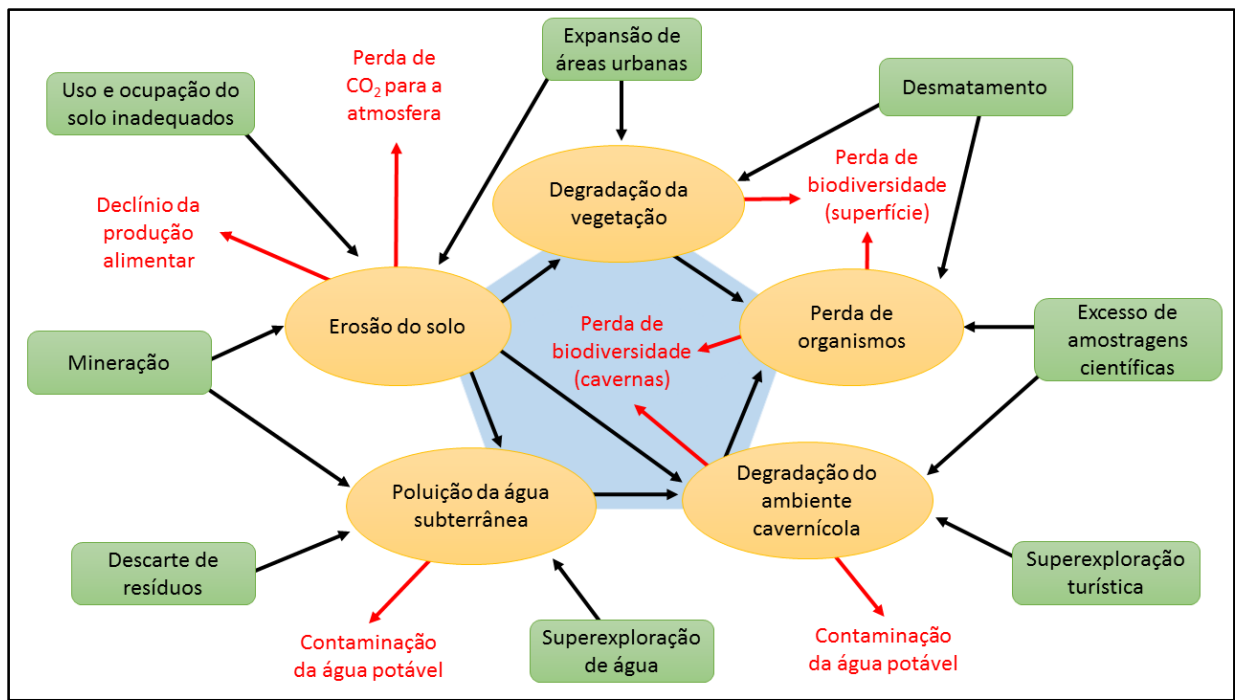

Figura 1: Esquema de impactos interligados que afetam o carste e os ecossistemas cavernícolas. Fonte: Elaborado pelos autores. Modificado de Goldscheider (2012) e Forti (2013).

Pelo exposto, é fácil perceber a relevância da pesquisa, visto que muitas das cidades médias de Minas Gerais desenvolvem-se sobre o carste carbonático sem que, na maioria das vezes, existam os cuidados necessários para sua proteção.

Sendo assim, a pesquisa analisa a disposição de resíduos sólidos urbanos (RSU) em Minas Gerais, de 2008 a 2015, especificamente em cidades médias que se desenvolvem sobre os carbonatos do Grupo Bambuí. Estabeleceu-se uma relação entre o direito fundamental à saúde e a necessidade de se proteger o carste e seus aquíferos para manutenção da qualidade ambiental nessas regiões.

Uma vez escolhido o tema, procedeu-se à identificação dos municípios mineiros que se desenvolvem sobre o Grupo Bambuí (rochas predominantemente carbonáticas), por meio do mapeamento das informações levantadas. Assim, chegou-se ao total de 167 municípios. Desses, foram identificados 34 cujas sedes são cidades médias e, dessas, 18 estão no carste. Analisando essa informação, percebe-se que das 16 sedes restantes, 8 estão próximas aos carbonatos do Grupo Bambuí e 8 estão distantes deles. 
Cruzando os dados do Censo do Instituto Brasileiro de Geografia e Estatística (IBGE) e do Programa "Minas Sem Lixões", fornecidos pela Fundação Estadual do Meio Ambiente (FEAM), foram elaborados mapas da disposição de RSU nas cidades médias de Minas Gerais no período de 2008 a 2015.

\section{As cidades médias do Grupo Bambuí, em Minas Gerais}

O Brasil possui várias regiões onde o carste é o relevo predominante. Em classificação inicial, Karmann (1994) afirma que o carste em carbonatos desenvolve-se em cerca de 7\% do território que podem ser divididos em 19 regiões (CECAV, 2011) com grupos e formações geológicas distintas. Dessas, o Grupo Bambuí destaca-se como o mais extenso, com uma área aproximada de $150.000 \mathrm{~km}^{2}$, abrangendo porções do centro oeste, norte e noroeste de Minas Gerais; leste do Distrito Federal; nordeste de Goiás; sudeste do Tocantins; e oeste da Bahia (TRAVASSOS, 2010; CECAV, 2011; TIMO, 2015; TRAVASSOS, 2019).

Especificamente em Minas Gerais, Piló (1997;1998;1999) afirma que da extensão nacional de aproximadamente 5 a $7 \%$ de carste em carbonatos, cabem ao estado cerca de 3 a $5 \%$, ou 17.600 a $29.419 \mathrm{~km}^{2}$. Justamente ao longo do Grupo Bambuí que se desenvolvem as cidades médias estudas nesta pesquisa.

Iglesias e Uhlein (2009) afirmam que o Grupo Bambuí (750-600 Ma) constitui a cobertura neoproterozoica de maior distribuição ao longo do Cráton do São Francisco. Representa uma associação de rochas sedimentares depositadas em extenso mar epicontinental. Regionalmente, foram identificadas as formações clássicas do Grupo Bambuí, conforme definido no Projeto Radambrasil (1982), tendo por base, mas com modificações, a estratigrafia proposta por Costa e Branco (1961) e Dardenne (1978). São ao todo, cinco formações clássicas do Grupo Bambuí, compreendendo, da base para o topo, as formações Sete Lagoas (carbonática), Serra de Santa Helena (pelito-carbonática), Lagoa do Jacaré (carbonática), Serra da Saudade (pelítica) e Três Marias (psamítica).

Em Minas Gerais, 34 (trinta e quatro) cidades médias se desenvolvem sobre as rochas do Grupo Bambuí, hierarquizadas em 3 (três) Cidades Médias de Nível Superior (Montes Claros, Patos de Minas e Sete Lagoas), 4 (quatro) Cidades Médias Propriamente Ditas (Curvelo, Formiga, Paracatu e Patrocínio) e 27 (vinte e sete) Centros Emergentes (Abaeté, Arcos, Bambuí, Boa Esperança, Bocaiúva, Bom Despacho, Brasília de Minas, Buritizeiro, Carmo do Paranaíba, Corinto, Espinosa, Janaúba, Januária, João Pinheiro, Lagoa da Prata, Luz, Paraopeba, Pirapora, Pitangui, Piumhi, Pompéu, Porteirinha, Santo Antônio do Monte, São Francisco, São Gotardo, Três Marias e Unaí). Desses municípios, 23 (vinte e três) deles apresentam suas sedes sobre o carste, de acordo com as bases geológicas oficiais (Figura 2 e 3). A classificação das cidades médias de Minas Gerais seguiu os trabalhos de Amorim Filho (1984), Amorim Filho, Bueno e Abreu (1982), Amorim Filho, Rigotti e Campos (2007) e Amorim Filho (2015). 


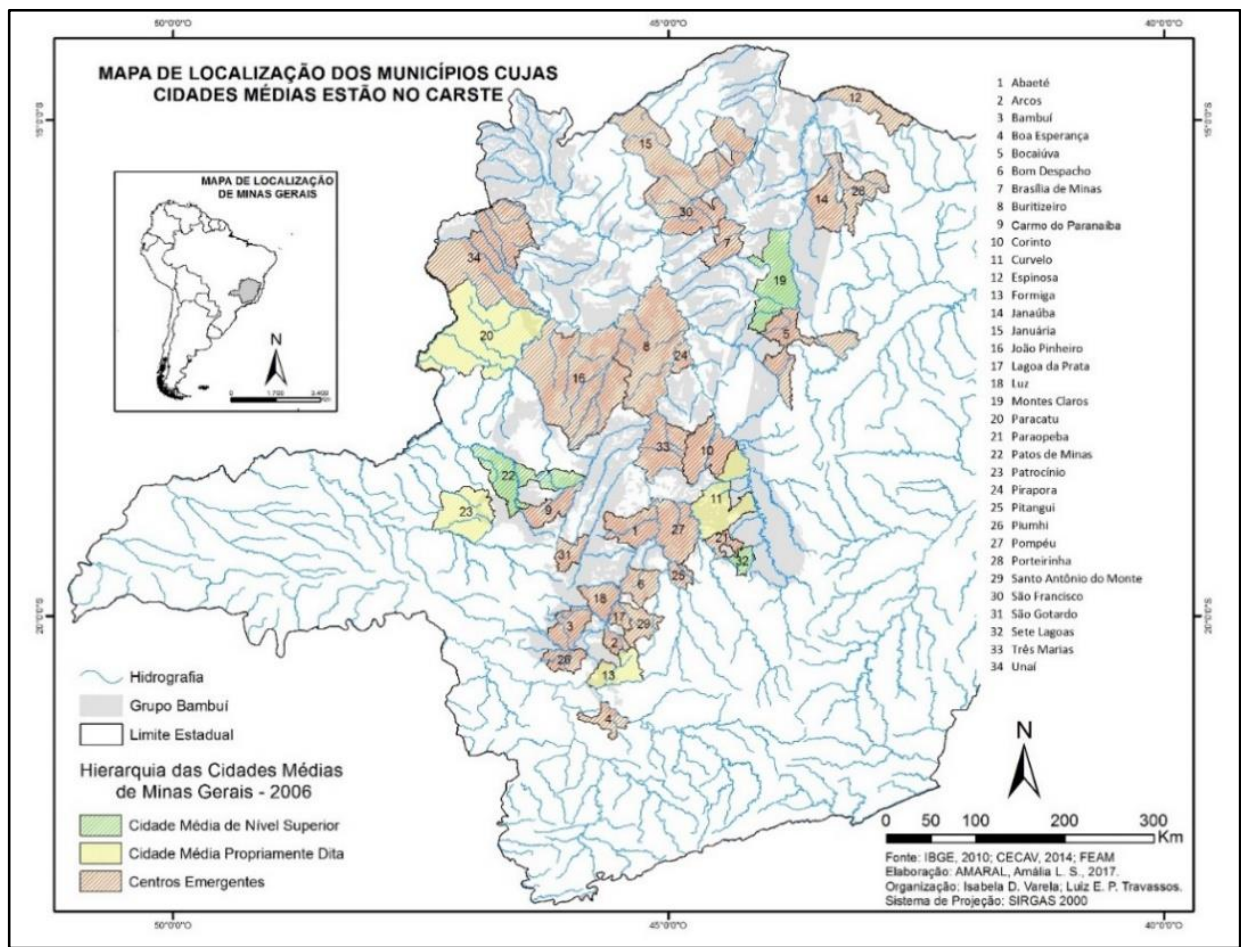

Figura 2: Distribuição espacial dos municípios mineiros e o Grupo Bambuí no estado de Minas Gerais Fonte: Elaborado pelos autores.

A presença de cidades em região cárstica não é fato aleatório, uma vez que o carste vem sendo utilizado desde a antiguidade para abrigar povos por diversos motivos. Sendo formado por rochas solúveis e possuindo água como um dos principais fatores para sua formação, o carste possui importantes reservas de água subterrânea. Durante as fases de recarga e descarga há um aumento e posterior diminuição do volume de água por onde materiais orgânicos podem ser deixados na superfície, tornando-a mais fértil para o plantio. Além disso, as cavernas, inicialmente procuradas como locais de abrigo e proteção, hoje são vistas como locais para a prática de turismo ecológico, religioso, entre outros. 


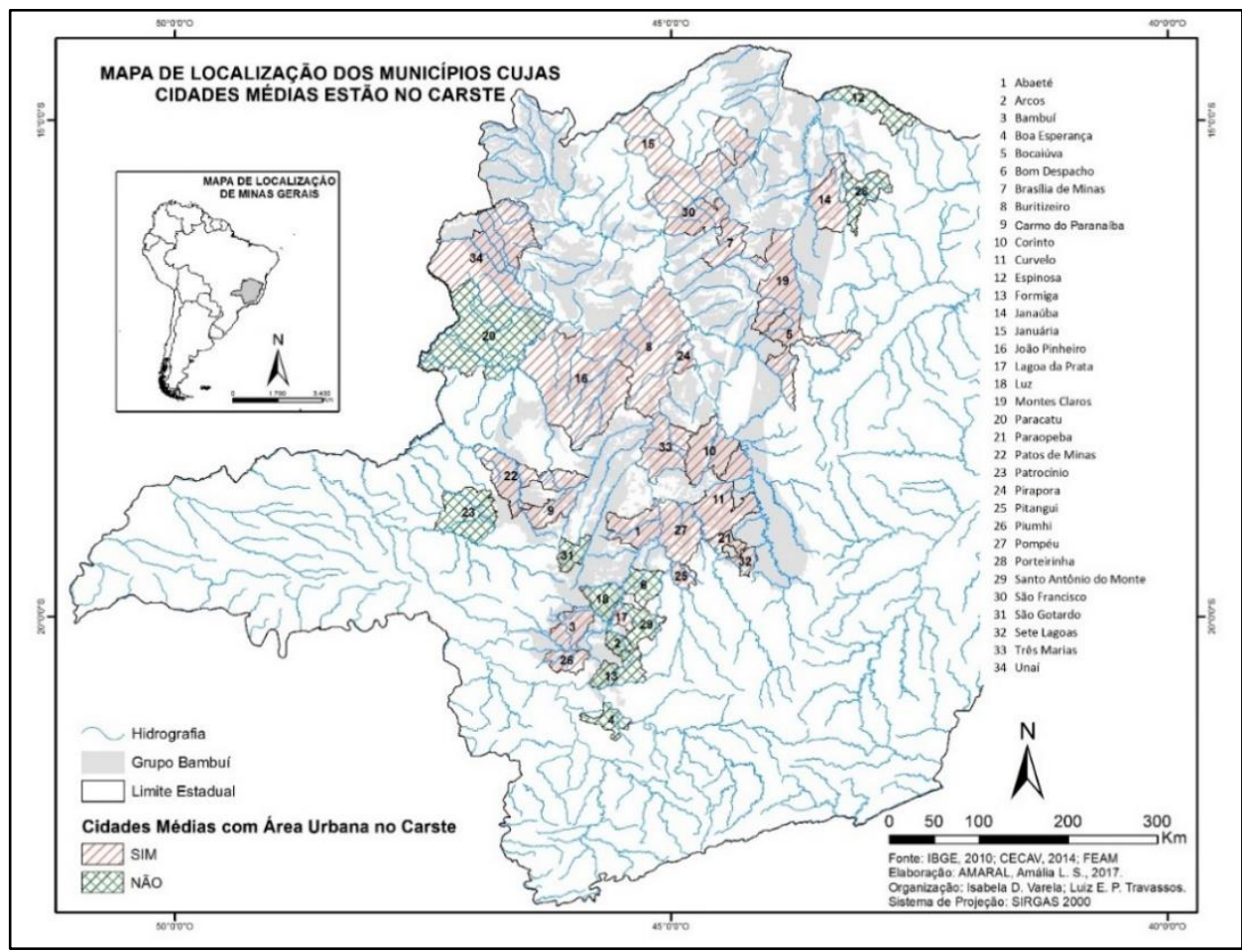

Figura 3: Distribuição espacial dos municípios mineiros que apresentam área urbana sobre o carste do Grupo Bambuí no estado de Minas Gerais.

Fonte: Elaborado pelos autores.

Se a utilização do carste para abrigar cidades não é uma vocação recente, as consequências de sua utilização foram se agravando com o tempo. O volume de pessoas, o número de construções, a utilização das águas subterrâneas e o lixo produzido teve aumento exponencial. Com isso, um relevo de beleza cênica única e que proporciona inúmeros benefícios vem sendo constantemente ameaçado pelo descarte inadequado de resíduos. Suas águas são utilizadas desordenadamente, construções destroem o patrimônio subterrâneo existente e as cavernas e demais feições cársticas são frequentemente vandalizadas.

\section{A disposição de resíduos sólidos nas cidades médias de Minas Gerais localizadas no Grupo Bambuí de 2008 a 2015}

As cidades médias possuem um papel fundamental na dinâmica regional por favorecerem a exploração econômica local e atuarem como mediadoras entre os grandes centros urbanos e as cidades pequenas. Percebe-se que muito do fluxo urbano que seria direcionado aos grandes centros é redirecionado para tais cidades e, isso ocorre, tendo em 
vista o fato de oferecerem serviços variados a públicos diversos. Assim sendo, é comum que as cidades médias absorvam a população do entorno.

As cidades médias mineiras desenvolvidas sobre os carbonatos do Grupo Bambuí contam com os benefícios de se situarem em uma região cárstica que fornece reservas de água subterrânea, depósitos minerais, áreas propícias para o plantio e locais de beleza cênica que favorecem o turismo.

Entretanto, com o crescimento dessas cidades, o aumento da produção de resíduos sólidos urbanos e seu descarte inadequado tornam-se um sério problema para a manutenção da qualidade ambiental. A contaminação dos mananciais subterrâneos, por exemplo, não atingiria somente os moradores desses centros urbanos, mas também, os moradores de outros centros que podem depender do mesmo manancial.

Assim sendo, é importante analisar os dados referentes ao abastecimento de água, tipo de esgotamento sanitário, quantidade de lixo produzido, quantidade de lixo coletado e como é feito o descarte de resíduos sólidos urbanos nas cidades médias selecionadas.

De acordo com o censo de 2010 realizado pelo IBGE, apenas três municípios que são objeto de estudo nesta pesquisa possuem entre $93,84 \%$ a 97,86\% de seus domicílios com abastecimento de água ofertado pela rede geral. São eles Lagoa da Prata, Pirapora e Sete Lagoas. Nove municípios ofertavam água pela rede geral a apenas 71,12\% a 82,02\% de seus domicílios, sendo eles Bocaiúva, Brasília de Minas, Carmo do Paranaíba, Espinosa, Januária, João Pinheiro, Porteirinha, São Francisco e Unaí.

O abastecimento de água realizado por poços ou nascentes é superior a $12,5 \%$, podendo chegar a até 20,4\% dos domicílios em treze municípios dessa região. Abaeté, Boa Esperança, Bocaiúva, Brasília de Minas, Carmo do Paranaíba, Januária, João Pinheiro, Luz, Paracatu, Patrocínio, Porteirinha, São Francisco e Unaí se encontram nessa situação.

Cumpre ressaltar que, de acordo com o relatório da FEAM para o ano de 2010, nenhum desses municípios possuía destinação final de resíduos sólidos adequada havendo, portanto, a possibilidade de contaminação das águas subterrâneas.

Outro dado que merece ser analisado e que foi levantado pelo IBGE no censo de 2010 é o tipo de esgotamento sanitário utilizado em domicílios particulares permanentes. A coleta de esgoto pela rede geral e a utilização de fossas sépticas e de fossas rudimentares são os meios mais comuns apontados pela pesquisa.

Em dezoito dos municípios estudados aqui, a rede geral é adotada para 72,93\% a $94,33 \%$ dos domicílios. No entanto, em sete municípios, menos que 16,8\% dos domicílios possuem coleta pela rede geral. Esse dado é preocupante, pois a coleta inadequada do esgoto poderá contaminar as águas subterrâneas.

A utilização de fossas rudimentares é uma saída mais barata do que a construção de fossas sépticas, e, em seis municípios, são utilizadas em mais de $48 \%$ de seus domicílios. Buritizeiro, Espinosa, Janaúba, Pirapora, Porteirinha e São Francisco são os 
que mais utilizam fossas rudimentares e que aparecem como alguns dos que não possuem rede geral de esgoto.

Deve ser destacado que Porteirinha e São Francisco possuem boa parte de seus domicílios com abastecimento de água por poços ou nascentes.

$\mathrm{O}$ uso de fossas sépticas ocorre em menor proporção do que a rede geral e as fossas rudimentares. Uma justificativa provável é o desconhecimento técnico e o custo mais elevado para construção de fossas sépticas. Em trinta e dois municípios, menos de $10 \%$ dos domicílios a possuem. Apenas em Corinto e Januária, de 10,11\% a 25,57\% de seus domicílios adotam tal sistema.

Dado de extrema importância para a temática desta pesquisa diz respeito ao destino do lixo dos domicílios particulares permanentes dos municípios. O Censo de 2010 apresentou diversas destinações possíveis sendo elas, lixo coletado, lixo coletado por serviço de limpeza, lixo coletado em caçamba, lixo queimado na propriedade, lixo enterrado na propriedade, lixo jogado em terreno baldio, lixo jogado em cursos d'água e outros destinos. Os que apresentam maior percentual de utilização são o coletado, o queimado na propriedade e o jogado em terreno baldio. Dessa forma, optou-se por analisar esses tipos de descarte.

Das cidades médias selecionadas na pesquisa, em 2010, apenas seis municípios apresentavam coleta de RSU superior a 92,60\%, sendo que em nenhum, verificou-se $100 \%$ dessa prestação de serviço. São eles: Arcos, Bom Despacho, Lagoa da Prata, Montes Claros, Pirapora, Piumhi e Sete Lagoas. Deve ser salientado que a existência de coleta de lixo não significa destinação adequada.

Com relação a esses municípios, apenas Arcos, Lagoa da Prata e Pirapora possuíam aterro sanitário à época do Censo. Os demais possuíam, em sua maioria, lixões. Assim, apesar de haver coleta de lixo, o descarte era realizado de forma incorreta, tornando-se um potencial contaminante do solo e dos mananciais de água.

Em 1,08\% a 10,8\% dos domicílios de sete municípios, o lixo é abandonado em terreno baldio, como ocorre em Bocaiúva, Brasília de Minas, Espinosa, Janaúba, Januária, Porteirinha e São Francisco. Já em dezessete municípios, de 10,07\% a 44,33\% dos domicílios utilizam a queima como forma de eliminar o lixo produzido.

O IBGE aponta que apenas 5 municípios possuem de 48,74\% a 60,18\% de domicílios com acesso a coleta de lixo. Essa é a menor faixa percentual para as cidades médias do Grupo Bambuí e são as cidades de Brasília de Minas, Espinosa, Januária, Porteirinha e São Francisco. Pelos dados analisados, percebe-se que essas são as mesmas cidades com maior índice de queima e abandono de lixo em terreno baldio.

Ao analisar os dados do IBGE, em conjunto, é possível perceber a constância de alguns municípios nos piores índices levantados. São eles: Bocaiúva, Brasília de Minas, Espinosa, Janaúba, Januária, Porteirinha e São Francisco. 
Outro dado que merece ser analisado é aquele referente ao volume de lixo coletado por dia e sua destinação. $\mathrm{O}$ que se tem disponibilizado referente a esse aspecto são os dados levantados pelo IBGE na Pesquisa Nacional de Saneamento Básico do ano 2000. Existem informações de apenas vinte e sete das trinta e quatro cidades médias estudadas neste trabalho.

De acordo com os dados, a cidade que menos coletou lixo foi Bambuí, com uma quantidade diária de 9 toneladas/dia. Já a cidade que mais coletou foi Montes Claros, com 384 toneladas/dia. Dessas vinte e sete cidades, apenas quatro coletaram um volume diário superior a 50 toneladas/dia, sendo elas: Janaúba, Januária, Montes Claros e Patos de Minas. Cumpre ressaltar que, à época, a maior parte desses resíduos, em todas as cidades mencionadas, era lançada em lixões ou aterros controlados.

Após a contextualização necessária em relação aos dados básicos de abastecimento de água, tipo de esgotamento necessário e quantidade de lixo produzido, coletado e sua forma de descarte, é possível ter uma visão melhor a respeito das cidades médias selecionadas para essa pesquisa

Por meio das informações oficiais, é possível considerar que as cidades exercem o papel de mediadoras entre as cidades pequenas e grandes, mas, muitas vezes, falta a infraestrutura necessária para manutenção da qualidade ambiental. Assim, é de fundamental importância acompanhar o seu crescimento e analisar se ocorre algum reflexo positivo para sua população.

O dado escolhido para visualizar esse crescimento foi a disposição final de RSU, tendo em vista que, dada a localização das cidades, os benefícios não ficariam restritos aos limites municipais podendo, também, ultrapassar a fronteira de Minas Gerais.

Cumpre ressaltar que em alguns momentos, foi feita a distinção entre os aterros controlados e os lixões, mas ambos são considerados formas de destinação de RSU ambientalmente inadequadas.

Outro esclarecimento importante é o fato de que algumas cidades médias pesquisadas não possuíam situação regularizada, ou seja, constavam como detentoras de Autorização Ambiental de Funcionamento (AAF) em verificação ou apresentavam aterros sanitários e UTCs pendentes de regularização. Nesse caso, também foram consideradas como possuidoras de disposição final inadequada, já que não cumpriram, ainda, todos os requisitos necessários.

\section{A Disposição de RSU nas Cidades Médias selecionadas}

Neste momento, deve ser lembrada a existência, desde 2001, da Deliberação Normativa (DN 52/2001) do Conselho Estadual de Política Ambiental de Minas Gerais. O documento havia estipulado um prazo para que os municípios com determinada faixa populacional apresentassem as licenças de operação dos locais adequados para o recebimento dos resíduos sólidos urbanos. Ressalta-se, ainda, que o Programa "Minas sem 
Lixões" foi idealizado, em 2003, pela FEAM, como forma de auxiliar os municípios a cumprirem as metas estabelecidas pela DN 52/2001.

De acordo com os dados disponibilizados pela FEAM, a realidade das trinta e quatro cidades médias selecionadas na pesquisa segue o mesmo padrão do restante dos municípios de Minas Gerais, ou seja, a ampla maioria não apresenta destinação adequada para os resíduos sólidos urbanos. Ao analisar a distribuição espacial dessas cidades em relação ao carste, percebe-se que estão espalhadas ao longo do Grupo Bambuí, fato que permite inferir que a contaminação é possível em vários pontos.

A pesquisa identificou que, em 2008, os lixões e aterros controlados eram a realidade para vinte e nove cidades. Na maior parte (vinte e duas) existia a pior destinação possível, ou seja, os lixões. Ressalta-se que apenas cinco possuíam aterro sanitário ou UTCs regularizadas (Figura 4).

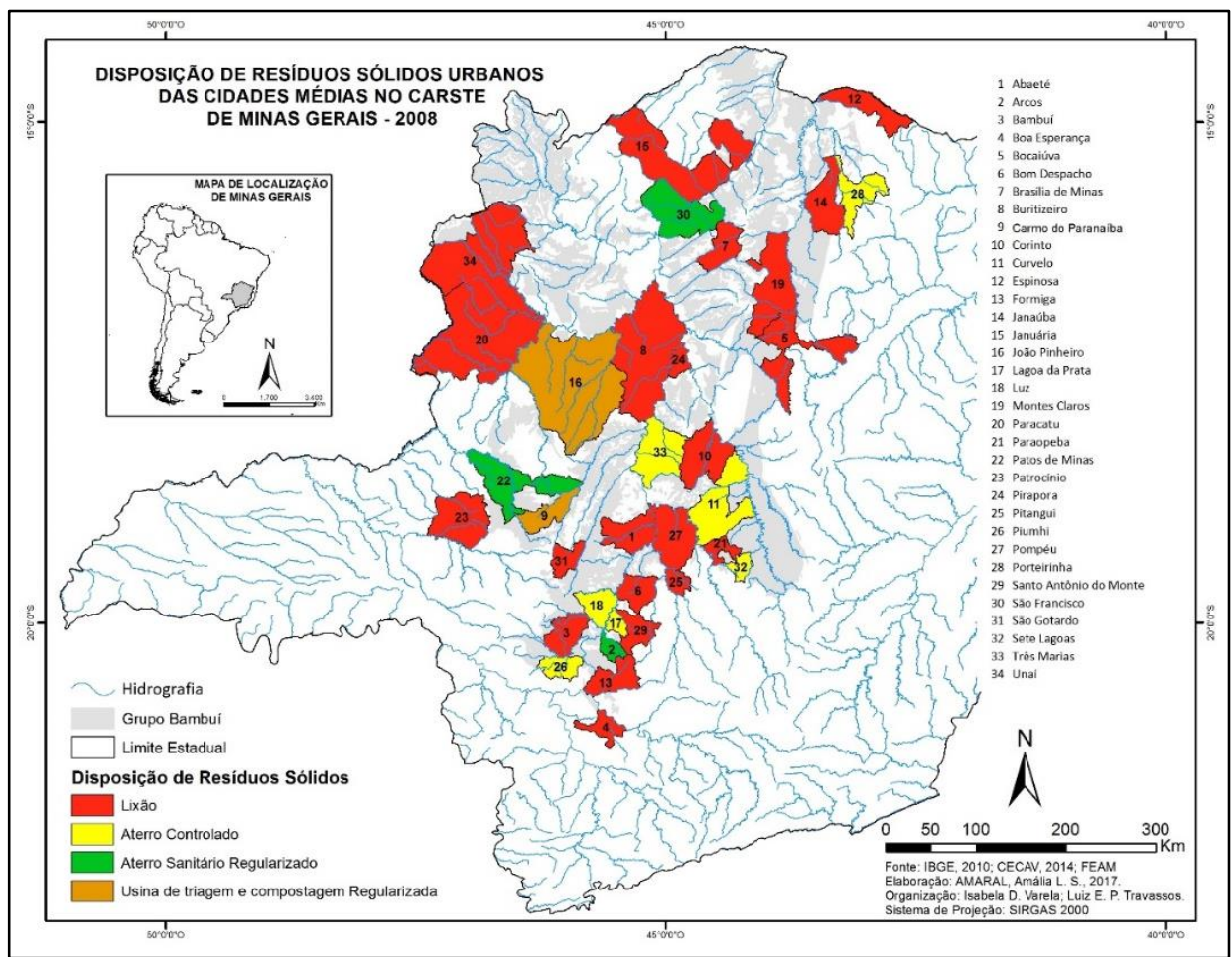

Figura 4: Distribuição espacial da tipologia de disposição de RSU nas cidades médias do carste mineiro.

Fonte: Elaborado pelos autores com dados da FEAM.

Levando em consideração a contagem da população residente realizada pelo IBGE (2007), nessas cidades vivem 1.985.393 habitantes. Ao confrontar essa informação 
com os dados da FEAM, 1.690.650 habitantes não possuíam acesso à disposição final adequada de resíduos sólidos urbanos.

Os municípios com maior faixa populacional, tais como Montes Claros (352.384 habitantes) e Sete Lagoas (217.506 habitantes) possuíam lixões e aterros controlados, respectivamente. Deve ser lembrado, ainda, que, de acordo com a Pesquisa Nacional de Saneamento Básico realizada em 2000 pelo IBGE, Montes Claros já recolhia e lançava em locais inadequados 384 toneladas de lixo por dia.

De acordo com os dados do IBGE (2007) em relação à contagem da população, $85,15 \%$ dos moradores das cidades não possuíam acesso ao descarte adequado de RSU de forma a evitar contaminação do solo e das águas subterrâneas e superficiais. Levando em consideração que boa parte desses municípios não possui tratamento de água para toda a população, isso se torna um sério problema potencial de saúde pública.

Ressalta-se que o carste é um sistema e que uma possível contaminação de suas águas não atingirá “apenas" o número mencionado de habitantes, atingindo diversas outras cidades pequenas, médias ou grandes de Minas Gerais ou de outros Estados-membros.

No ano de 2009, a Lei n ${ }^{\circ}$ 18.031, que estabeleceu a Política Estadual de Resíduos Sólidos, foi publicada e há a continuidade do Programa Minas sem Lixões pela FEAM.

Ao analisar a distribuição espacial da tipologia de disposição de RSU nas cidades selecionadas, é possível perceber algumas modificações em relação ao ano anterior, mas ainda, há predominância da adoção dos sistemas inadequados.

Foram, à época, dezoito cidades utilizando lixões, oito com aterros controlados, quatro com aterros sanitários regularizados e outras quatro com AAF em verificação.

Algumas cidades, tais como Bambuí, Bom Despacho, Montes Claros, Paracatu, Paraopeba e Pitangui passaram a utilizar aterros controlados ao invés de lixões, o que configura uma pequena melhoria na forma de descarte, mas há a manutenção de um sistema inadequado.

Carmo do Paranaíba, Curvelo, João Pinheiro, Piumhi, Porteirinha, São Francisco, Sete Lagoas e Três Marias, contudo, regrediram em seu status. Tais cidades possuíam aterros controlados e UTCs e, no caso de São Francisco, aterro sanitário. Todas passaram a possuir lixões ou ter sua AAF em verificação. As duas cidades que despontaram foram niga e Pirapora, haja vista que ambas, em 2008, possuíam lixões e agora passam a contar com aterros sanitários.

Em termos populacionais, apesar de existir o aumento de um município com aterro sanitário, houve um decréscimo no número de habitantes usufruindo de um sistema ambiental adequado de disposição de RSU.

Tal circunstância se verifica pelo fato dos dois municípios que possuíam UTCs terem seu status modificado para AAF em verificação. Como a autorização ambiental de funcionamento requer revalidação periódica e o município pode não a conseguir novamente, é inviável considerar que eles se encontram em situação regularizada (Figura 5). 


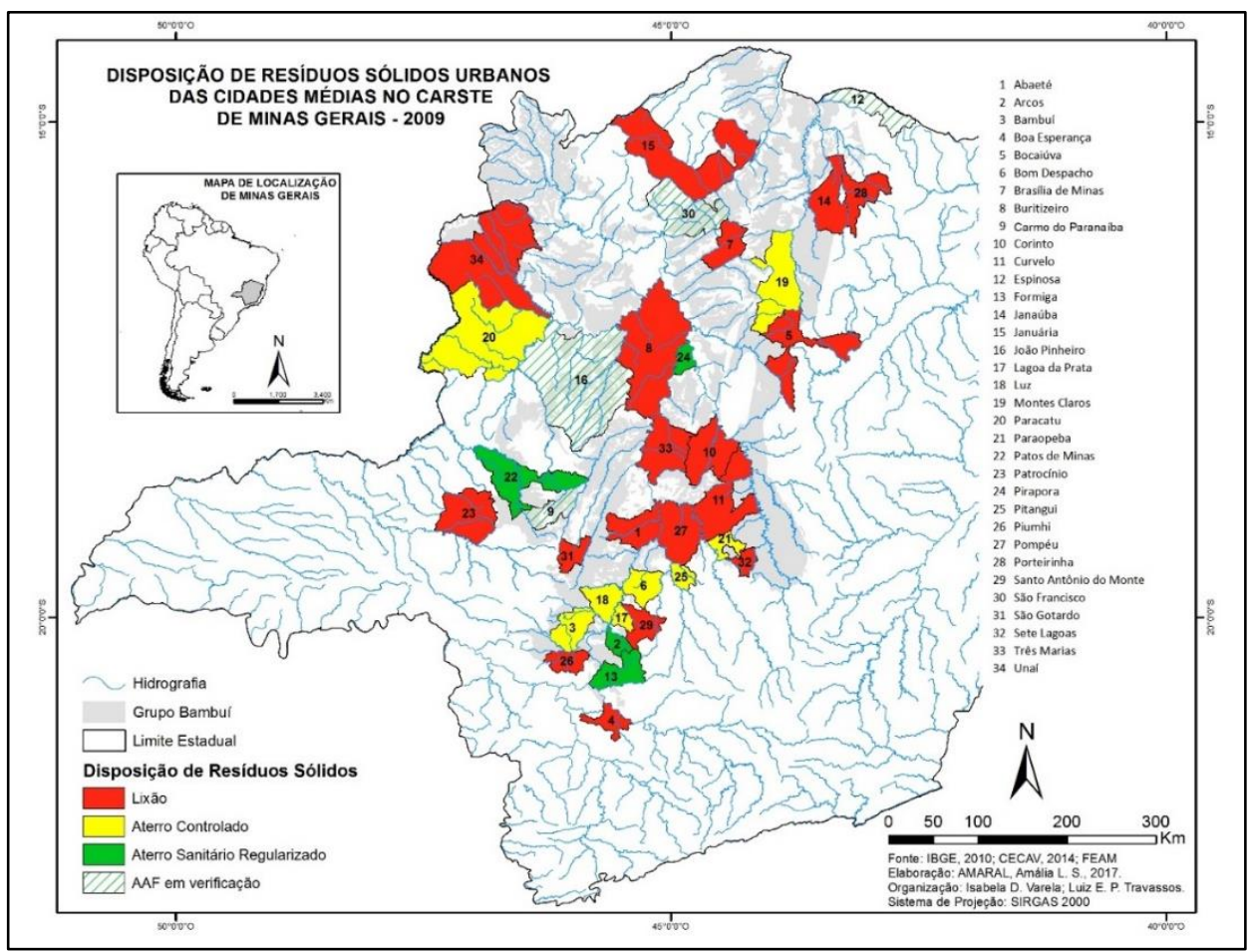

Figura 5: Distribuição espacial da tipologia de disposição de RSU nas cidades médias do carste mineiro.

Fonte: Elaborado pelos autores com dados da FEAM.

Assim, apenas 284.038 moradores dessa região se encontram em situação adequada ao passo que, em 2008, eram 294.743. Devido ao fato de se ter reduzido o número de cidades com lixões, o número de pessoas que utilizam tal sistema de descarte também diminuiu. Contudo, ampliou-se o número de cidades com aterro controlado e quatro passaram a ter sua $\mathrm{AAF}$ em verificação.

Dessa forma, a contagem final de habitantes utilizando um sistema inadequado passou para 1.701.354, ou seja, mais 10.704 moradores que no ano anterior. Em termos percentuais isso representa $85,7 \%$ da população em detrimento dos $85,15 \%$ de 2009 .

Um ano após a publicação da Política Estadual de Resíduos Sólidos de Minas Gerais e no ano em que a Política Nacional de Resíduos Sólidos entrou em vigor, a situação das cidades médias do carste mineiro não apresentou evolução substancial.

Em 2010, observou-se vinte e quatro cidades com disposição final inadequada ao passo que, em 2009, eram vinte e seis. A diferença de duas cidades corresponde a Bambuí e Lagoa da Prata que passaram a contar com aterros sanitários. As cidades médias que estavam com AAF em verificação (Carmo do Paranaíba, Espinosa, João Pinheiro e São Francisco) permaneceram nessa condição. 
Há um aumento no número de lixões em detrimento da diminuição de aterros controlados, mas, se for levado em consideração o critério da disposição ser ambientalmente adequada ou não, o número de cidades com alocação final inadequada diminuiu. Bom Despacho e Montes Claros que, em 2009, possuíam aterros controlados passaram a contar com lixões, mantendo, portanto, uma alocação final de RSU inadequada. Assim, o quadro final da disposição de resíduos sólidos urbanos nas cidades médias do carste mineiro passou a contar com vinte e um lixões, três aterros controlados, seis aterros sanitários e 4 municípios com AAF em verificação (Figura 6).

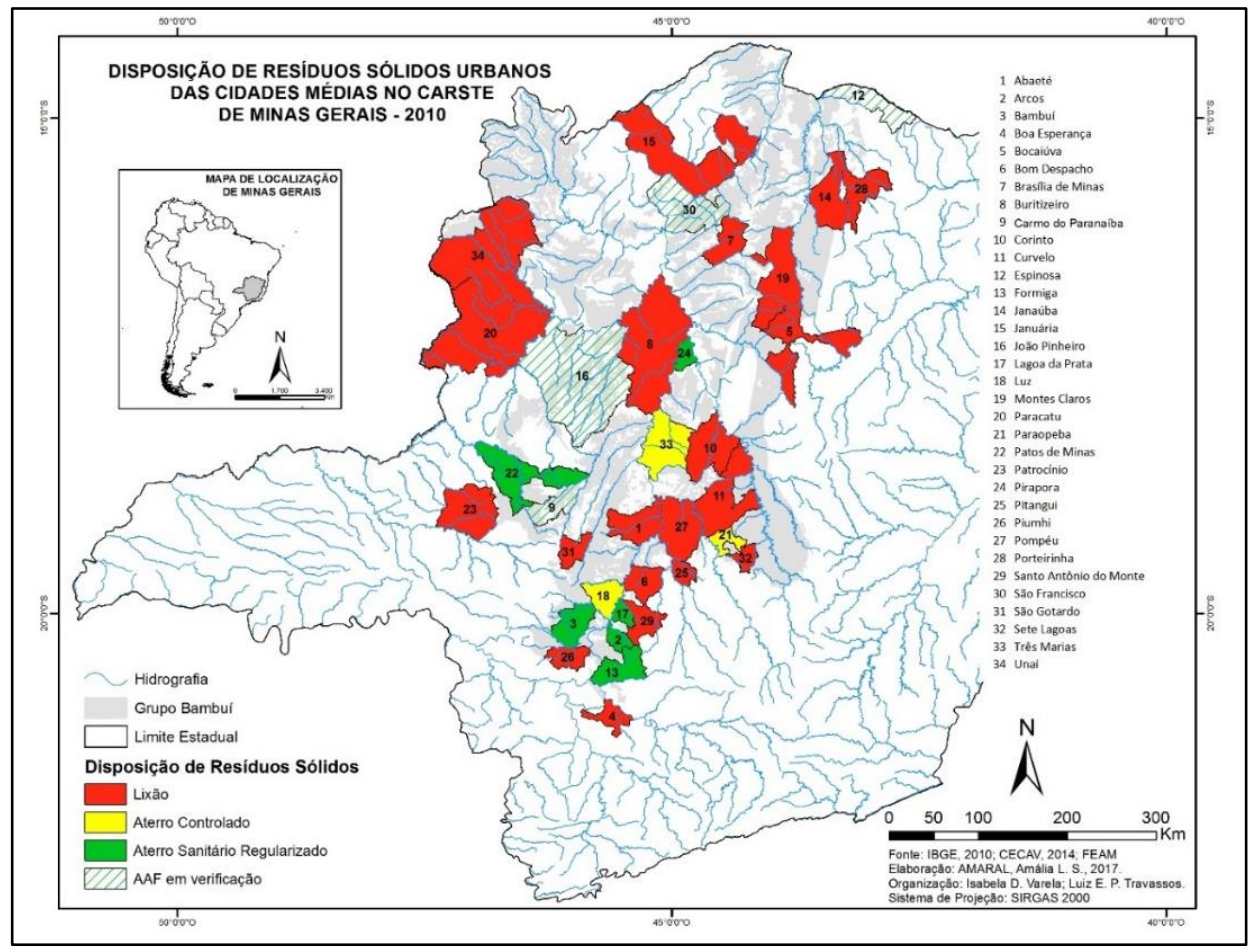

Figura 6: Distribuição espacial da tipologia de disposição de RSU nas cidades médias do carste mineiro.

Fonte: Elaborado pelos autores com dados da FEAM.

Ao fazer uma análise comparativa da evolução das cidades em relação ao ano anterior, é possível perceber que quatro mantiveram disposição adequada, vinte e oito mantiveram disposição inadequada e duas progrediram para alocação final adequada.

Apesar do alto número de cidades em situação ambientalmente incorreta, há um avanço, pois nenhuma regrediu de adequada para inadequada.

Outro dado relevante é o número crescente de cidades em que foi implementada a utilização de aterros sanitários. Arcos e Patos de Minas, desde 2008, possuem aterro sanitário funcionando. As cidades de Formiga e Pirapora implementaram aterro sanitário 
em 2009 e os mantiveram em 2010. O único município que no relatório da FEAM de 2008 constava como possuidor de aterro sanitário e não o manteve em 2010, foi São Francisco.

Em 2009 essa faixa representava 604.387 habitantes ao passo que, em 2010, apenas 68.367. A diminuição desse segmento levou a um pequeno aumento do número de pessoas que passaram a contar com aterros sanitários e um aumento mais elevado do número que tiveram a situação de seus municípios piorada. Cumpre salientar que tais dados populacionais já estão atualizados com o Censo do IBGE de 2010.

Tal quadro reflete o aumento do número de cidades com lixão, passando de dezoito para vinte e um, a diminuição de aterros controlados, de oito para três, e o aumento de cidades com aterros sanitários, de quatro para seis. Em termos percentuais, há uma evolução no quadro geral, pois, de $85,7 \%$ da população, há uma redução para $82,2 \%$ de habitantes com sistema ambientalmente inadequado de alocação final de RSU.

Ao analisar o mapa referente à distribuição espacial da destinação final de resíduos sólidos das cidades médias mineiras localizadas no Grupo Bambuí de 2011 (Figura 7), é possível perceber uma evolução em relação ao ano de 2010.

Percebe-se uma redução do número de lixões e um aumento do número de aterros controlados e aterros sanitários. Em 2011 foram dezoito lixões, seis aterros controlados, sete aterros sanitários e três cidades com AAF em verificação.

No entanto, se a análise for realizada em relação à disposição adequada e inadequada, a variação foi de apenas dois municípios. Sete Lagoas deslocou-se para o segmento das cidades médias com disposição adequada ao colocar em funcionamento seu aterro sanitário. Arcos, em contrapartida, regrediu ao apresentar um lixão. 


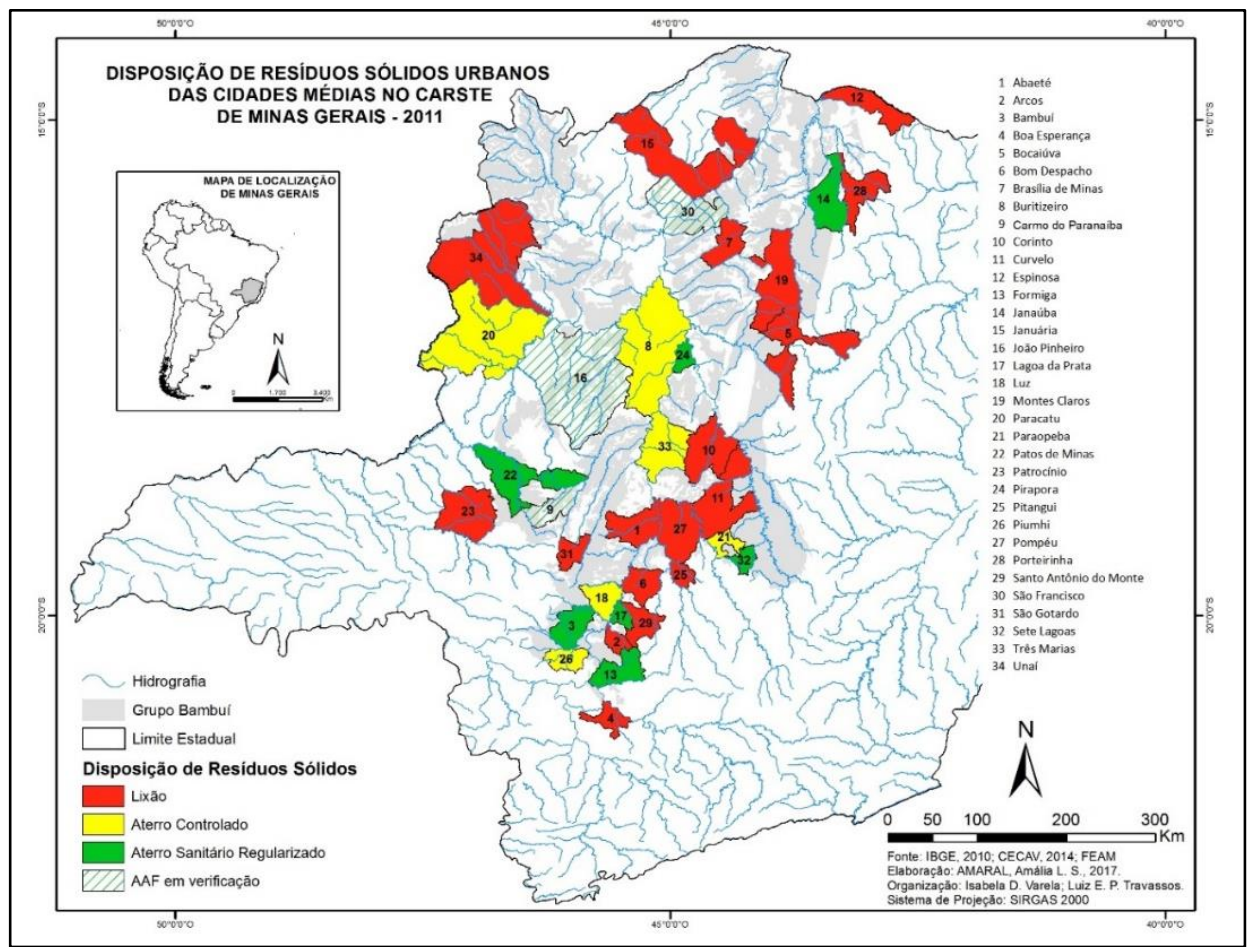

Figura 7: Distribuição espacial da tipologia de disposição de RSU nas cidades médias do carste mineiro

Fonte: Elaborado pelos autores com dados da FEAM.

Assim, vinte e seis cidades mantiveram descarte inadequado, cinco permaneceram com alocação final adequada, uma progrediu ao implementar um aterro sanitário e outra regrediu ao voltar a possuir lixão.

Deve ser lembrado que uma das metas da Política Estadual de Resíduos Sólidos (PERS) era a redução de $80 \%$ do número de lixões para 2011. No âmbito estadual, já foi demonstrado que esse objetivo não foi cumprido.

Com relação às cidades analisadas, esse marco também não foi atingido. Em 2008 foram identificadas vinte e duas cidades com lixões ao passo que, em 2011, foram dezoito. Para que a meta fosse cumprida seria permitida a existência de apenas quatro municípios com lixões. Com relação ao número de habitantes, houve uma redução significativa daqueles que utilizam lixão como forma de descarte final.

Na faixa onde o lixão é o sistema adotado, foi identificada uma redução de 356.768 habitantes em relação ao ano anterior, sendo que ocorreu um aumento de 143.523 munícipes utilizando aterros controlados e um acréscimo de 244.358 pessoas usufruindo de aterros sanitários. 
Em termos percentuais, a evolução, de 2010 para 2011, é mais perceptível ainda. Em 2010, 82,2\% da população conviviam com um processo de descarte inadequado ao passo que em 2011 esse número foi reduzido para 70,19\%.

Se por um lado, o objetivo da PERS para 2011 não foi alcançado, de outro, é visível um progresso na situação dessas cidades. Entretanto, cidades importantes como Bocaiúva, Bom Despacho, Curvelo, Januária, Montes Claros, Paracatu, Patrocínio, São Francisco e Unaí, que possuem população variando de 45.000 a 361.000 habitantes, permaneceram com disposição inadequada de RSU.

Ao analisar os dados disponibilizados pelo IBGE na PNSB, de 2000, verifica-se que naquele ano as cidades destacadas coletavam parte do lixo produzido sendo que esse montante representava 639,1 toneladas/dia. É correto deduzir que, no decorrer de onze anos, a produção de resíduos sólidos aumentou, haja vista o próprio crescimento populacional de cada uma dessas cidades.

Assim, apesar do progresso apresentado pelos dados de 2011, a quantidade de lixo descartado de forma incorreta foi substancial e os danos à saúde e ao meio ambiente gerados não podem ser ignorados.

A situação dos municípios em 2012, de acordo com os dados da FEAM, não apresentou muita alteração. Foi possível identificar a permanência de dezoito cidades utilizando lixões, a redução de uma cidade com aterro controlado, o aumento de uma com aterro sanitário regularizado, uma cidade adotando UTC regularizada, uma com AAF em verificação e uma última cidade com aterro sanitário não regularizado (Figura 8).

As modificações apresentadas referem-se à Curvelo, Carmo do Paranaíba, Paraopeba, João Pinheiro e Arcos.

Curvelo possuía, em 2011, um lixão e, em 2012, dispunha de um aterro sanitário. Carmo do Paranaíba apresentava uma AAF em verificação e passou a dispor de UTC regularizada. Paraopeba regrediu ao ter seu aterro controlado reclassificado como lixão. João Pinheiro não obteve sucesso em sua AAF e seu sistema de disposição final de RSU foi classificado como lixão. Por fim, Arcos passou a contar com um aterro sanitário não regularizado, em 2012.

Levando em consideração que os sistemas não regularizados não devem ser considerados como adequados, é correto afirmar que vinte e cinco cidades mantiveram o descarte inadequado de resíduos sólidos urbanos, sete permaneceram com alocação adequada e duas progrediram para adequada. 


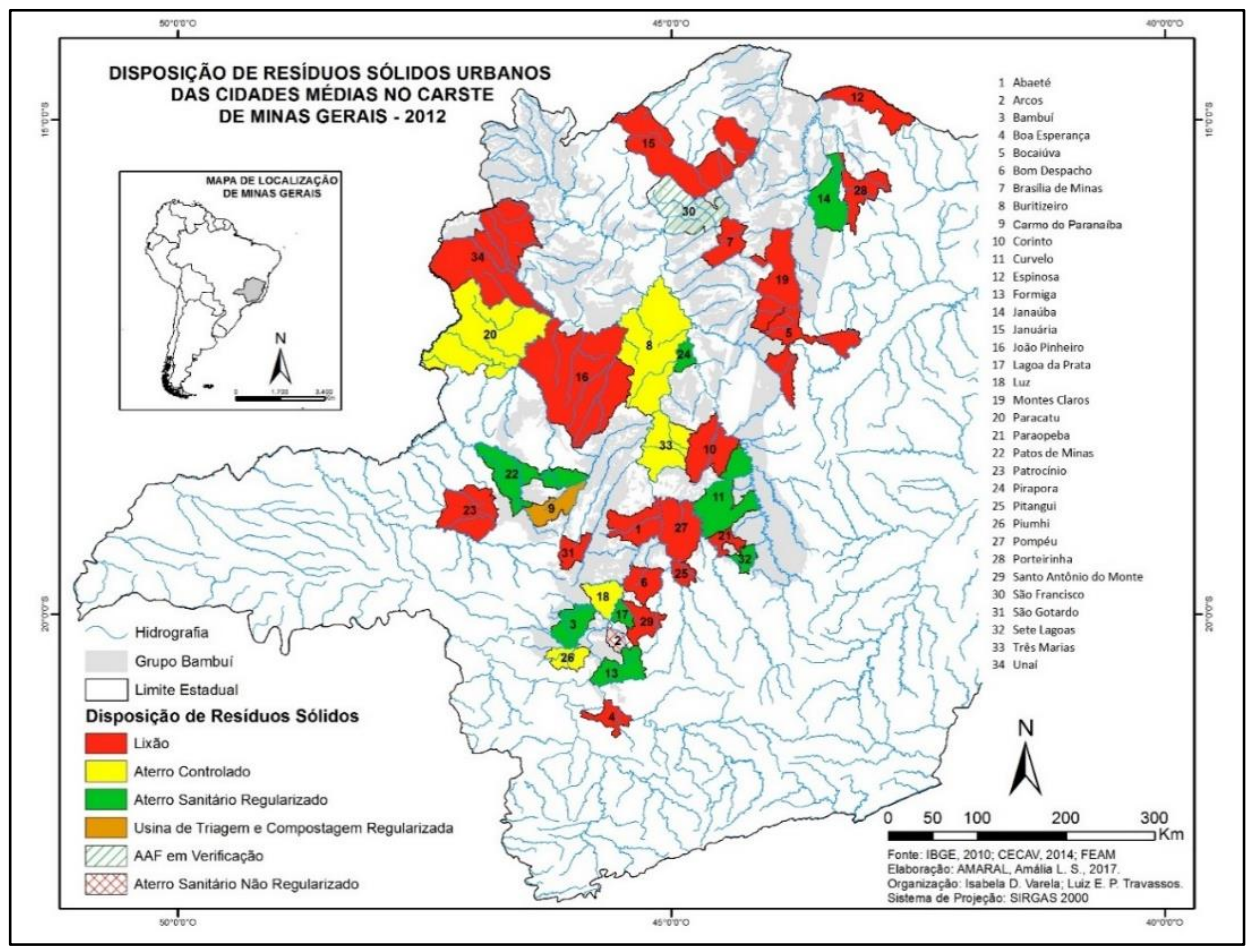

Figura 8: Distribuição espacial da tipologia de disposição de RSU nas cidades médias do carste mineiro

Fonte: Elaborado pelos autores com dados da FEAM.

Com relação ao número de habitantes, ocorreu uma ampliação dos beneficiados com uma destinação adequada passando para 710.833 habitantes. No que se refere àqueles que ainda contam sistemas ambientalmente inapropriados, há uma redução, mas permanecem ainda 1.324 .550 pessoas nessa situação.

Há um visível crescimento da população que usufrui de forma de alocação de resíduos sólidos não prejudiciais à saúde e ao meio ambiente. Entretanto, em termos percentuais, mais da metade $(65,07 \%)$ dos residentes dessas cidades ainda não contavam com esse tipo se serviço. Esse fato é preocupante tendo em vista os graves problemas ambientais e de saúde que podem decorrer dessa situação.

No ano de 2013, dezoito cidades permaneceram com lixão e cinco com aterro controlado. Foi possível identificar o progresso de uma cidade e, com isso, observou-se nove cidades com aterros sanitários. Ocorreu a manutenção de uma cidade com aterro sanitário não regularizado e outra com AAF em verificação.

As cidades que tiveram a situação modificada foram Carmo do Paranaíba e Pitangui. A primeira, em 2012, usufruía de uma Usina de Triagem e Compostagem 
Regularizada e, em 2013, regrediu para a situação de ter AAF em verificação. Pitangui, ao contrário, progrediu de lixão, em 2012, para aterro sanitário, em 2013 (Figura 9).

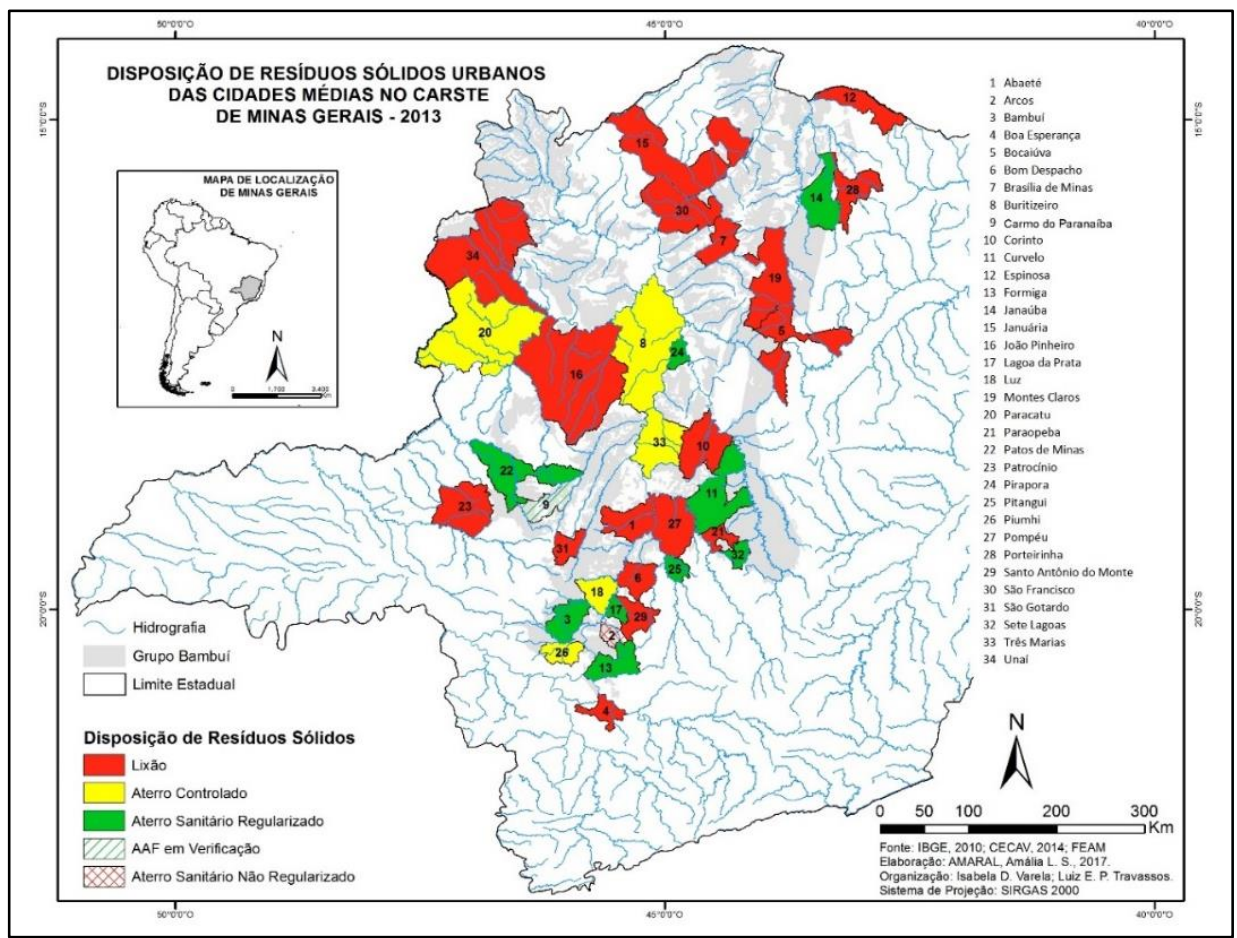

Figura 9: Distribuição espacial da tipologia de disposição de RSU nas cidades médias do carste mineiro

Fonte: Elaborado pelos autores com dados da FEAM.

São Francisco, no ano anterior, estava em situação pendente, pois apresentava AAF em verificação que foi negada e sua disposição de RSU foi classificada como lixão. Contudo, conforme mencionado anteriormente, para efeito deste trabalho sua situação não foi alterada, pois já era considerada inadequada.

Assim, é correto afirmar que, em 2013, vinte e quatro cidades permaneceram com disposição final inadequada, oito mantiveram-se adequadas, uma progrediu e outra teve sua situação piorada.

No tocante à população, 1.328.974 moradores não usufruíam de uma destinação correta, ou seja, ocorreu um pequeno aumento em relação ao ano anterior. Em contrapartida, percebeu-se uma pequena queda do número de habitantes que contavam com o descarte adequado, perfazendo um total de 706.409 habitantes. Essa pequena variação representou, em termos percentuais, que $65,30 \%$ dos residentes não possuíam uma alocação final de RSU ambientalmente correta e que apenas $34,70 \%$ a dispõem. 
Em 2014, das trinta e quatro cidades analisadas, dezenove possuíam lixão, cinco se mantiveram com aterro controlado, oito contavam com aterro sanitário, uma possuía UTC regularizada e outra permaneceu com aterro sanitário não regularizado (Figura 10).

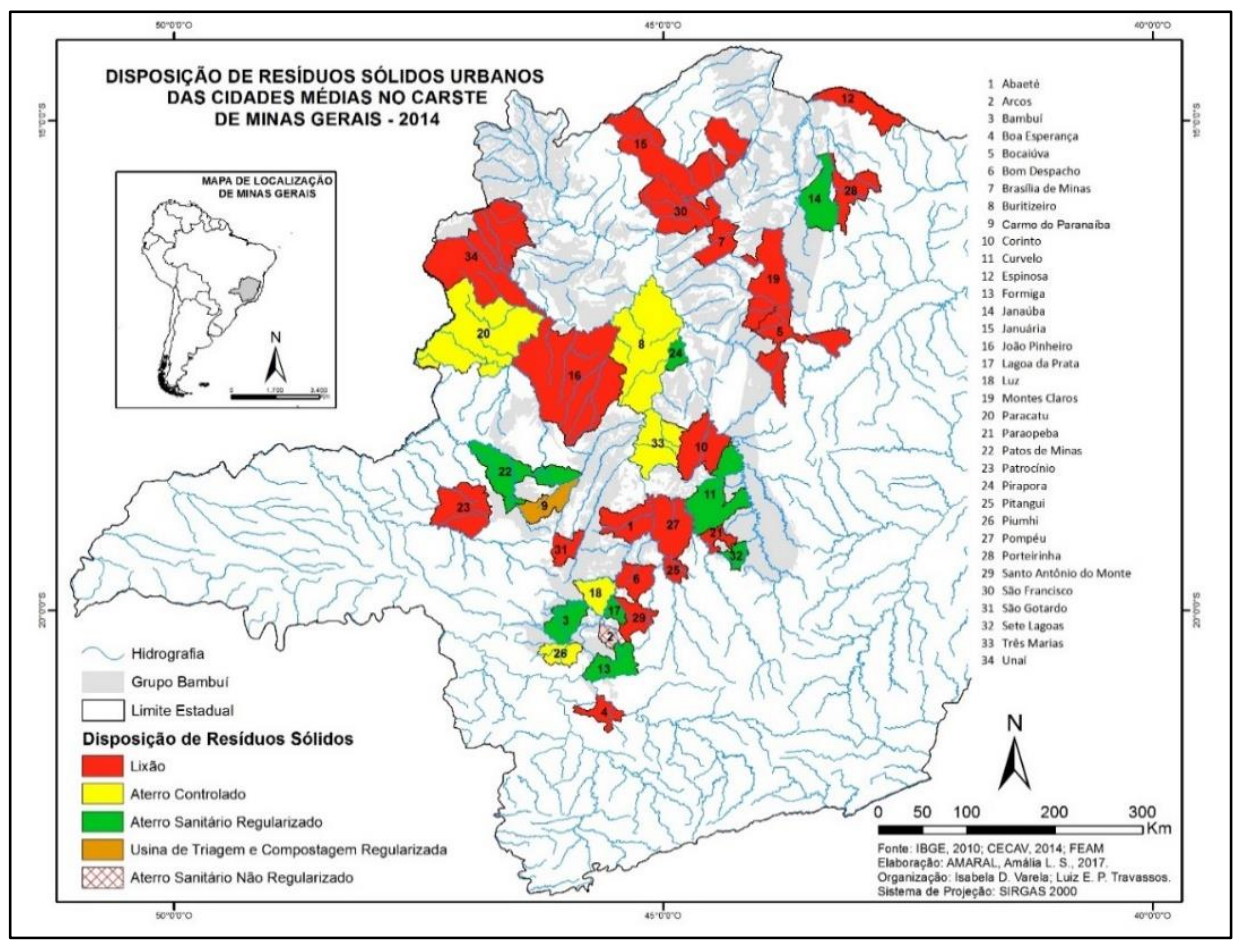

Figura 10: Distribuição espacial da tipologia de disposição de RSU nas cidades médias do carste mineiro

Fonte: Elaborado pelos autores com dados da FEAM.

As duas cidades que tiveram sua condição modificada em 2013 (Pitangui e Carmo do Paranaíba) também foram as que apresentaram mudanças em 2014. Contudo, a situação nesse ano foi inversa.

Carmo do Paranaíba, que estava com AAF em verificação, voltou a possuir uma UTC Regularizada. Já Pitangui, que no ano anterior apareceu no Relatório da FEAM como detentora de aterro sanitário, voltou para sua condição de 2012, apresentando um lixão como forma de descarte.

Dessa forma, vinte e quatro cidades mantiveram a alocação inadequada, oito permaneceram ambientalmente adequadas, uma regrediu e outra progrediu, ou seja, a mesma variação do ano anterior. É possível concluir que, retirando Carmo do Paranaíba e Pitangui, as demais cidades permaneceram como estavam em 2013. 
Esse cenário reflete uma inércia do Poder Público Municipal na tentativa de melhorar a qualidade de vida e de saúde de seus cidadãos, pois, pelo menos nesse quesito, não foi possível perceber investimento nítido.

Com a análise dos dados é possível perceber um aumento do segmento populacional que utilizava o lixão como descarte e uma diminuição daqueles que tinham acesso a aterro sanitário. Contudo, em termos gerais, percebe-se uma ligeira ampliação da faixa populacional beneficiada com a destinação adequada: são 34,93\%, em 2014, contra os $34,70 \%$, em 2013.

O descarte inadequado, por sua vez, atinge $65,07 \%$ em 2014, contra os $65,30 \%$ de 2013. Tais números retratam a aparente estagnação das cidades nos investimentos em saneamento.

Não se deve esquecer que o ano de 2014 foi o escolhido no PNRS para se ter a ausência total de lixões em território nacional. Da mesma forma que, em 2011, a meta estadual não foi cumprida, em 2014, não se cumpriu a meta nacional.

Em 2015, o Relatório da FEAM mostra que das trinta e quatro cidades, dezoito permaneceram com lixão e cinco com aterro controlado. Oito cidades apresentaram aterro sanitário regularizado, uma possuía UTC regularizada e duas dispunham de aterro sanitário não regularizado (Figura 11).

Apesar dos números serem bastante parecidos com a situação de 2014, em 2015, foi possível identificar alterações substanciais. A maior delas diz respeito a Montes Claros, que é a maior cidade em termos populacionais das trinta e quatro analisadas. Em 2015, pela primeira vez no período estudado, apresentou destinação final de RSU adequada ao implementar um aterro sanitário. Em contrapartida, Patos de Minas, outra importante cidade e que nos últimos anos estava no grupo das possuidoras de aterro sanitário, foi "rebaixada" para o rol das inadequadas ao passar a apresentar aterro sanitário não regularizado.

Assim, é possível afirmar que vinte e quatro cidades permaneceram inadequadas e oito adequadas. Uma cidade progrediu e outra regrediu. Tem-se, portanto, a mesma evolução de 2013 e 2014. Contudo, em termos populacionais, foi possível perceber uma diferença enorme devido à alteração de Montes Claros. Em 2014, cerca de 1.098.626 residentes destinavam seus resíduos sólidos em lixão. Em 2015, esse número caiu para 736.711 habitantes. A faixa populacional que utiliza aterro controlado permaneceu inalterada. 


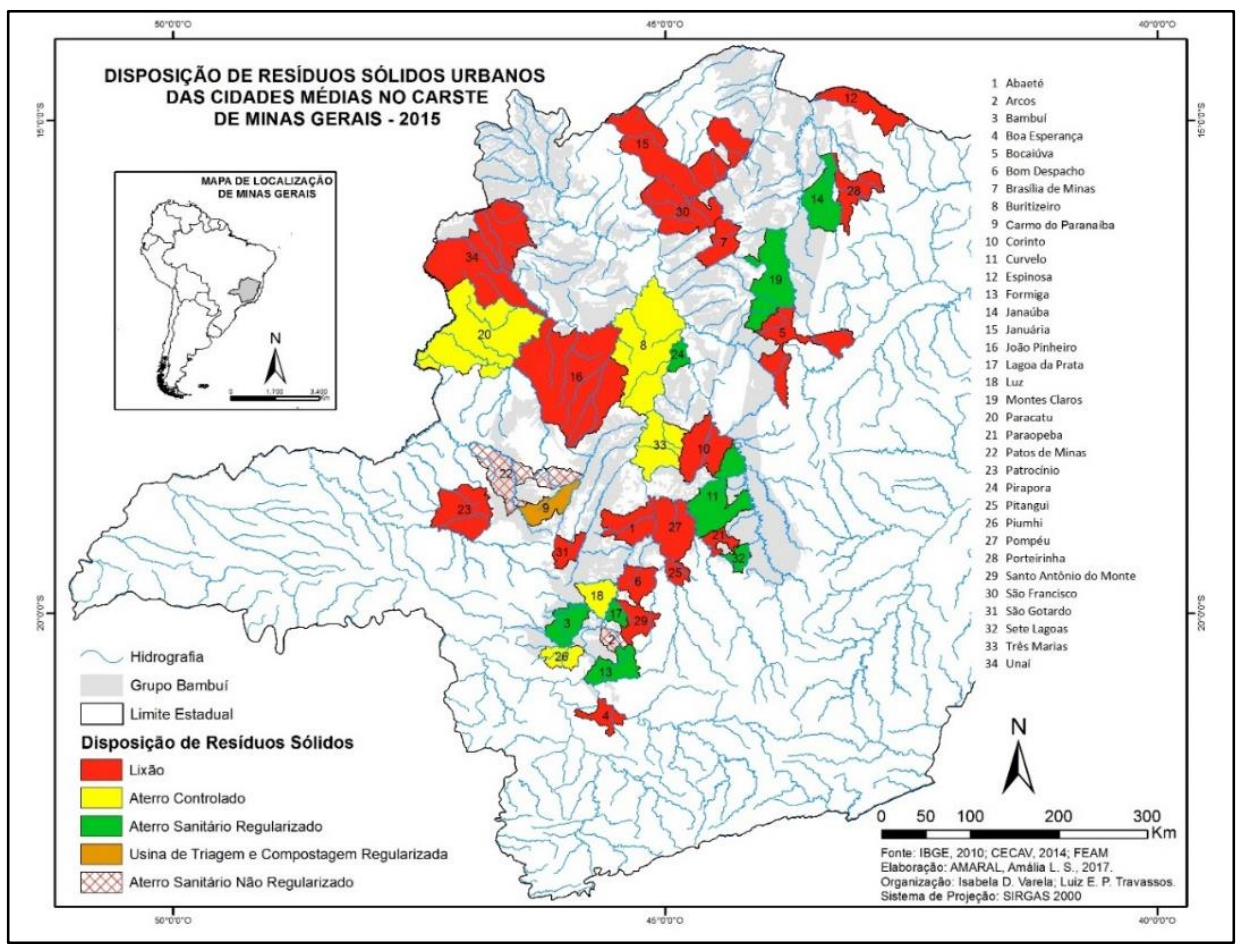

Figura 11: Distribuição espacial da tipologia de disposição de RSU nas cidades médias do carste mineiro

Fonte: Elaborado pelos autores com dados da FEAM.

Já no segmento de residentes que faziam uso de aterros sanitários, percebeu-se um salto para 904.303, contra os 710.833 moradores de 2014. No total, 1.101.345 munícipes possuíam acesso a destinação inadequada, contra 934.038 que possuíam destinação ambientalmente correta para RSU.

Tais alterações, em termos percentuais, representam uma elevação do segmento em que é disponibilizada uma destinação adequada, ou seja, em 2015, são 45,89\% dos residentes. Por outro lado, 54,11\% dos moradores permaneceram em situação desfavorável.

Observa-se, portanto, uma mudança no quadro geral das cidades relacionadas, pois, pela primeira vez, foi possível identificar um número maior de residentes em municípios com aterros sanitários, do que aqueles com lixões. Contudo, levando em consideração as outras formas de descarte, existia, ainda, uma prevalência do número de pessoas sem o acesso ambientalmente adequado de alocação final de RSU.

Com relação ao número de cidades, vinte e cinco, ou seja, a maior parte, não adotava um sistema capaz de manter o equilíbrio ambiental necessário para a preservação 
do carste e das águas subterrâneas de forma a não gerar danos à saúde pública, ao meio ambiente das mesmas e de outras cidades.

Assim, ao fazer a análise dos dados disponibilizados pela FEAM, percebe-se que a Política Nacional de Resíduos Sólidos, bem como o Plano Estadual de Resíduos Sólidos, não obtiveram sucesso nas cidades médias analisadas.

\section{Conclusões}

Partindo de uma concepção sobrenatural que relacionava saúde e doença ao humor dos deuses, passando pelos trabalhos revolucionários de Hipócrates e Galeno, pelo retrocesso da Idade Média, pela retomada do racionalismo científico do Renascimento, pelo desenvolvimento da iatroquímica e iatromecânica e pela utilização do microscópio, até ser a saúde vista como parte integrante de uma política nacional, o caminho é longo.

Percebe-se, então, a ocorrência de uma mudança de visão: no início, o homem nada podia fazer, pois estava à mercê dos deuses e a sua preocupação girava em torno da doença; não, da saúde. Posteriormente, essa percepção vai sendo ampliada e a saúde prevalece em detrimento da doença. Assim é delineada a perspectiva que relaciona o homem ao seu meio, o qual influencia na qualidade de vida e, por conseguinte, na saúde da população.

Para esta pesquisa foi adotada uma visão ampla, que apresenta o meio ambiente como um conjunto de elementos naturais e artificiais necessários ao desenvolvimento pleno, harmônico, solidário e duradouro dos seres humanos e demais seres vivos. A interação entre os meios biótico, abiótico e o homem deve, portanto, ser feita de forma racional, visando à manutenção e o equilíbrio do meio.

A existência da relação saúde humana e meio ambiente não é questionável. Claro que muitas doenças são decorrentes de opções de vida e não guardam relação com questões ambientais, mas um meio ambiente saudável e equilibrado evita grande parte delas. Outro fato que não deve ser ignorado é que mesmo que uma conduta inadequada do homem com o meio ambiente não ocasione diretamente males a outros seres humanos, haverá dano ambiental e, por conseguinte, prejuízos incalculáveis.

Com a pesquisa, nota-se que muitos dos avanços conquistados pela sociedade brasileira continuam apenas no papel. A meta estabelecida pela PNRS, de que em 2014 não haveria mais a presença de lixões no território nacional, está longe de ser alcançada. Em Minas Gerais, o cenário não é diferente. A meta constante do PERS previa, para o ano de 2011, uma redução de $80 \%$ dos lixões, fato que a pesquisa demonstrou não ter ocorrido.

A utilização de lixões ou aterros controlados como forma de descarte final de resíduos sólidos urbanos, não é uma boa opção, devido ao fato desses locais se tornarem lugares propícios à proliferação e dispersão de insetos e roedores, que são hospedeiros e transmissores de diversas doenças. Além disso, não existem mecanismos eficientes que impeçam a contaminação do solo e das águas. 
No caso específico das cidades que são objeto de estudo da pesquisa, a utilização de lixões e aterros controlados é ainda pior, devido à sua tipologia e ao embasamento geológico.

Com relação aos dados levantados durante a pesquisa, e levando em consideração todo o período analisado, chega-se a algumas conclusões importantes:

O principal problema científico da pesquisa é destacar o fato de que as cidades médias se apresentam como fontes potenciais de contaminação do carste, muito em função do aumento populacional e a consequente geração de resíduos sólidos urbanos;

Das trinta e quatro cidades, vinte delas sempre se mantiveram com disposição inadequada de RSU;

Oito cidades efetivamente atuaram no sentido de melhorar a forma de descarte, passando de inadequadas para adequadas;

Quatro cidades regrediram, tornando-se inadequadas; uma delas era adequada, foi rebaixada para inadequada e posteriormente recuperou sua situação anterior;

Uma cidade era inadequada, apresentou progressos, mas, posteriormente, voltou a ser classificada como inadequada.

É possível perceber, ao analisar os dados elencados ao longo do trabalho, que algumas cidades nunca se dispuseram a melhorar sua situação, enquanto outras apresentaram retrocesso. Vários fatores podem servir de justificativa para os respectivos prefeitos, mas não há como negar a parcela de responsabilidade do governo estadual, ausente na fiscalização rigorosa do cumprimento das metas impostas.

A implementação da perspectiva de um desenvolvimento sustentável mediante, a adoção de práticas que promovam a sustentabilidade, tem orientado os governantes a adotarem formas planejadas de crescimento e uso do meio ambiente nos centros urbanos. As cidades são uma espécie de organismo vivo, cujo desenvolvimento ocorre diuturnamente e, consequentemente, gera problemas sociais e degradação ambiental contínua. Daí a necessidade de um planejamento rigoroso de política urbana e seu respeito na aplicação e fiscalização.

Levando-se em consideração as limitações temporais, documentais e financeiras, destacam-se alguns pontos que não foram contemplados nessa etapa e servem como norteadores para futuras pesquisas:

De que forma ocorreram os processos de ocupação e as dinâmicas econômica e demográfica das cidades médias no carste do Grupo Bambuí?

É desejável o desenvolvimento de pesquisas sistemáticas que comprovem a contaminação dos mananciais cársticos em função do lixiviado proveniente de aterros controlados e lixões, a exemplo das pesquisas realizadas em Yucatán (México) e Málaga 
(Espanha). Tais pesquisas devem ser orientadas no sentido de relacionar volume, natureza e tipologia da disposição de resíduos com os níveis de contaminação apresentados.

Do ponto de vista espacial, seria interessante identificar os locais de disposição de RSU e sua proximidade com feições cársticas de recarga, como os sumidouros ou entradas de cavernas verticais. Acredita-se que uma pesquisa nesse sentido proporcionaria dados para facilitar a compreensão dos resultados mencionados no item 2 .

Dessa forma, dados da pesquisa demonstram ser urgente, não apenas a construção de modelos sustentáveis nos aspectos ambiental, social e econômico, mas políticas a serem efetivamente seguidas e cumpridas por todos, governantes e governados, em todas as esferas, pois só assim haverá viabilidade ecossistêmica capaz de assegurar e manter a qualidade de vida humana e o equilíbrio do meio ambiente.

\section{Referências}

AMORIM FILHO, O. B. Cidades médias do Brasil. Revista Geografia e Ensino, Belo Horizonte: IGC/UFMG, v. 3, n. 2, 1984.

AMORIM FILHO, O.B. A Evolução dos Estudos sobre Cidades Médias em Minas Gerais. In: SATHLER, D.; AMORIM FILHO, O.B.; VARAJÃO, G.F.D.C. Cidades médias: bases teóricas e estudos aplicados à Diamantina. Belo Horizonte: Fino Traço, 2015. p.11-85.

AMORIM FILHO, O. B.; BUENO, M. E. T.; ABREU, J. F. de. Cidades de porte médio e o programa de ações sócioeducativo-culturais para as populações carentes do meio urbano em Minas Gerais. Boletim de Geografia Teorética, Rio Claro, v. 12, n. 23/24, p. 33-46, 1982.

AMORIM FILHO, O.B.; RIGOTTI, J.I.R.; CAMPOS, J. Os níveis hierárquicos de cidades médias de Minas Gerais. $R A$ 'E GA, Curitiba, n.13, p. 7-18, 2007.

AURELI, A. The UNESCO IHP's Shared Aquifer Resources Management Global Project AQUAmundi, n.1, p.1-6, 2010.

BARTON, H.A.; NORTHUP, D.E. Geomicrobiology in cave environments: past, current and future perspectives. Journal of Cave \& Karst Studies, v.69, n.1, p.163-178, 2007.

BRASIL. Lei no 6938, de 31 de agosto de 1981. Dispõe sobre a Política Nacional do Meio Ambiente, seus fins e mecanismos de formulação e aplicação, e dá outras providências.

Diário Oficial da União, Brasília, 31 de agosto de 1981. Disponível em:

<http://www.planalto.gov.br/Ccivil_03/Leis/L6938compilada.htm>

CECAV - Centro Nacional de Pesquisa e Conservação de Cavernas. Base digital de dados geoespacializados de cavernas do Brasil, 2011. Instituto Chico Mendes. Disponível em: <http://www.icmbio.gov.br/cecav/projetos-e-atividades/provincias-espeleologicas.html>. Acesso em 07 abr. 2015.

CIGNA, A.A., FORTI, P. Caves: the most important geotouristic feature in the world. Tourism and Karst areas, v.6, n.1, p.9-26, 2013. 
COSTA, B. S. Meio ambiente como direito à vida: Brasil, Portugal e Espanha. Belo Horizonte: O Lutador, 2010.

COSTA, W. Avaliação da viabilidade técnica de coprocessamento de resíduos sólidos de curtumes contaminados com cromo em fornos de cimenteira. 2009. Dissertação (Mestrado), PPGEMA, UFG, 2009.

COSTA, M.T.; BRANCO, J.J.R. Introdução. In: BRANCO, J.J.R. (Ed.) Roteiro para a excursão Belo Horizonte - Brasília. SBG: Belo Horizonte, 1961.

CRUZ, S.S. da; HUPFFER, H.M.; JAHNO, H.M. Destinação final de resíduos sólidos industriais: panorama do coprocessamento no Brasil. In: FORUM INTERNACIONAL DE RESÍDUOS SÓLIDOS, 7, 2016. Anais... Porto Alegre: Instituto Venturi, 2016. p.1-7.

DARDENNE, M.A. Síntese sobre a estratigrafia do Grupo Bambuí no Brasil Central. In: CONGRESSO BRASILEIRO DE GEOLOGIA, 30, Recife, Anais..., SBG: Recife, 1978. p. 507-610.

DONAIRE, D. Considerações sobre a influência da variável ambiental na empresa. Revista de Administração de Empresas (RAE), v. 34, n. 2, p. 68-77, 1994.

FEAM - FUNDAÇÃO ESTADUAL DO MEIO AMBIENTE. Panorama da destinação de resíduos sólidos urbanos em Minas Gerais: relatório de progresso - ano base 2011. Belo Horizonte: FEAM, 2012. Disponível em: http://www.feam.br/images/stories/ minas_sem_lixoes/2013/novo/relatorio_executivo_panorama_rsu_2011.pdf Aceso em: 20 jan. 2016.

FEAM - FUNDAÇÃO ESTADUAL DO MEIO AMBIENTE. Panorama da destinação dos resíduos sólidos urbanos no estado de Minas Gerais em 2013. Belo Horizonte: FEAM, 2014. Disponível em: http://www.feam.br/images/stories/minas_sem_lixoes/ Publicacoes2014/relatrio\%20de\%20progresso\%20\%20panorama\%20rsu_2013_gerub.pdf Aceso em: 20 jan. 2016.

FEAM - FUNDAÇÃO ESTADUAL DO MEIO AMBIENTE. Panorama da destinação dos resíduos sólidos urbanos no estado de Minas Gerais em 2014. Belo Horizonte: FEAM, 2015b. Disponível em: http://www.feam.br/images/stories/2015/MINAS_SEM _LIXOES/ARQUIVOS/relatorio-de-\%20progressopanorama\%20rsu_2015_gerub_fpf. pdf Aceso em: 20 jan. 2016.

FEAM - FUNDAÇÃO ESTADUAL DO MEIO AMBIENTE. Situação de Tratamento elou Disposição Final dos Resíduos Sólidos Urbanos Minas Gerais, 2015. Belo Horizonte: FEAM, 2015a. Disponível em: http://www.feam.br/images/stories/2016/ RESIDUOS/MINAS_SEM_LIX\%C3\%95ES/mapa_res\%C3\%ADduos_2015_site.pdf Aceso em: 20 jan. 2016.

FORD, D.; WILLIAMS, P. Karst Hydrogeology and Geomorphology. England: John Wiley \& Sons Ltd, 2007. 
FORTI, P. The scientific and socio-economic importance of karst and caves and their vulnerability. Brief for GSDR, 2015.

IBGE- Instituto Brasileiro de Geografia e Estatística. Arranjos populacionais e concentrações urbanas do Brasil. Rio de Janeiro: Ministério do Planejamento, Orçamento e Gestão, 2015. Disponível em: www.ibge.gov.br/apps/arranjos_popul acionais/2015. Acesso em 15 mar 2015.

IBGE- Instituto Brasileiro de Geografia e Estatística. Contagem da População 2007. 2.ed. Rio de Janeiro: Ministério do Planejamento, Orçamento e Gestão, 2007. Disponível em: http://biblioteca.ibge.gov.br/visualizacao/livros/liv93420.pdf. Acesso em 15 mar 2015.

IBGE- Instituto Brasileiro de Geografia e Estatística. Pesquisa Nacional de Saneamento Básico. Rio de Janeiro: Ministério do Planejamento, Orçamento e Gestão, 2010.

IGLESIAS, M.; UHLEIN, A. Estratigrafia do Grupo Bambuí e coberturas fanerozóicas no vale do rio São Francisco, norte de Minas Gerais. Revista Brasileira de Geociências, v. 39, n. 2, p. 256-266, 2009.

KARMMAN, I. Evolução Dinâmica Atual do Sistema Cárstico do Alto Vale do Ribeirade Iguape, Sudeste do Estado de São Paulo. 1994. 228f. Tese (Doutorado) - Universidade de São Paulo, Instituto de Geociências, São Paulo.

MINAS GERAIS. Conselho Estadual de Política Ambiental. Deliberação Normativa n ${ }^{\circ} 52$ de 14 de dezembro de 2001. Convoca municípios para o licenciamento ambiental de sistema adequado de disposição final de lixo e dá outras providências. Minas Gerais: Diário do Executivo, 15 dez. 2001. Disponível em: http://www.siam.mg.gov.br/sla/ download.pdf?idNorma $=5479$

MINAS GERAIS. Lei n. 18031 de 12 de janeiro de 2009. Dispõe sobre a Política Estadual de Resíduos Sólidos. Minas Gerais: Diário do Executivo, 13 jan. 2009. Disponível em: http://www.siam.mg.gov.br/sla/download.pdf?idNorma=9272

PARISE, M.; PASCALI, V. Surface and subsurface environmental degradation in the karst of Apulia (southern Italy). Environ. Geol., v.44, p.247-256, 2003.

PIPAN, T.; CULVER, D.C. Forty years of epikarst: what biology have we learned? International Journal of Speleology, v.42, n.3, p.215-223, 2013.

RAVBAR, N.; GOLDSCHEIDER, N. Comparative application of four methods of groundwater vulnerability mapping in a Slovene karst catchment. Hydrogeology Journal, v.17, n.3, p.725-733, 2009.

SHERWOOD, S.; SIMEK, J. Cave Archaeology in the Eastern woodlands. v.26, n.2, p.135, 2001.

SILVA, R.C.P. da.; COSTA, A.R.S.; MELLO, D.P. de; SILVA, R.G. da; EL-DEIR, S. Gestão de resíduos sólidos urbanos no exterior e no Brasil: uma análise comparativa do case em Recife-PE. In: FORUM INTERNACIONAL DE RESÍDUOS SÓLIDOS, 7, 2016. Anais... Porto Alegre: Instituto Venturi, 2016. p.1-10. 
SOUZA, J.C.R.; PINHEIRO, S.M.G. RODRIGUES, A.C.; MELLO, D.P.; SILVA, R.G. da; AQUINO, J.G. de; El-DEIR, S.G. Papel das políticas públicas no gerenciamento dos resíduos sólidos. In: FORUM INTERNACIONAL DE RESÍDUOS SÓLIDOS, 7, 2016. Anais... Porto Alegre: Instituto Venturi, 2016. p.1-10.

TIMO, M.B. O Carste da Região de Córrego do Cavalo, Piumhi, Minas Gerais, Brasil. Saarbrücken: Novas Edições Acadêmicas, 2015.

TRAVASSOS, L.E.P. Considerações sobre o carste da região de Cordisburgo, Minas Gerais, Brasil. Belo Horizonte: Tradição Planalto, 2010.

TRAVASSOS, L.E.P. Princípios de Carstologia e Geomorfologia Cárstica. Brasília: ICMBio, 2019.

UNESCO. Textos Fundamentales. Paris, 2014. Disponível em: http://unesdoc.unesco .org/images/0022/002269/226924s.pdf\#page=7 Acesso em: 10 abr. 2017

WHITE, W.B. Karst hydrology: recent developments and open questions. Eng. Geol., v.65, p.85-105, 2002.

Isabela Dalle Varela

Doutora em Geografia pela PUC Minas, Professora da Academia da Polícia Militar de Minas Gerais, do Centro Universitário Newton Paiva e da Faculdade de Direito Promove.

E-mail: dallevarela@gmail.com

Luiz Eduardo Panisset Travassos

Bolsista de Produtividade em Pesquisa do CNPq. Doutor em Carstologia pela Universidade de Nova Gorica (Eslovênia). Professor adjunto do Departamento de Geografia da PUC Minas, onde também atua como docente permanente no Programa de Pós-Graduação em Geografia - Tratamento da Informação Espacial.

Avenida Dom José Gaspar 500, Coração Eucarístico, Belo Horizonte, Minas Gerais. CEP: 30535901

E-mail: luizepanisset@gmail.com

Recebido para publicação em agosto de 2010 Aprovado para publicação em outubro de 2020 